\title{
Visual analysis as a tool for urban intervention in comparative studies
}

\author{
Ana Elena Builes Vélez ${ }^{1}$, Leonardo Correa Velásquez ${ }^{2}$, \\ Diana Carolina Gutiérrez Aristizabal ${ }^{1}$ \\ ${ }^{1}$ Facultad de Diseño de Vestuario. Universidad Pontificia Bolivariana. Medellín. Colombia; \\ ${ }^{2}$ Facultad de Artes Integradas, Programa de Arquitectura, Universidad de San Buenaventura, \\ Bello. Colombia \\ E-mail: ana.builes@upb.edu.co, leonardo.correa@usbmed.edu.co, \\ dianitaguti_456@hotmail.com
}

\begin{abstract}
In recent years, urban design development has been an important topic in Latin American cities such as Medellin, Mexico City and Córdoba, due to the transformation of their urban spaces and new methods used to evaluate the social, morphological and, in some cases, economic impacts that have been brought about by urban development projects. When inquiring about the development process and impact of urban studies, and the inhabitants' relation to a transformed space, it is important to establish the context within which images, drawings and photographs are analyzed, using graphical approaches triangulated with other research methods to define comparative criteria. Also, this paper will show, another example were visual analysis tools where used to understand urban transformation regarding economic process.
\end{abstract}

Keywords: Visual analysis, comparative studies, urban intervention, photography analysis.

\section{Methodology}

The research projects in which the research group used visual analysis had as object of study the city's urban transformation and its impact in social tissue, cultural and economic process. One of the projects involved comparing different Latin-American cities, its main goal was to acknowledge the impact of urban transformations on five different cities, compare them to find similarities and differences, and define criteria that will help determine whether an urban intervention project responds effectively to social innovation concepts. Achieving this requires an analysis of the space/spaces in which, according to Kuri \& Aguilar (2006), the following approaches were necessary:

1. An understanding of the space/spaces as areas with multiple meanings.

2. An analysis from a socio-cultural point of view that allows comprehending the elements of the identities of particular subjects.

3. Specifying transformations over time.

4. Relating them to broader contexts.

Latin-American cities have been transformed by phenomena like superposition, change, disappearance, imposition and, simultaneously, by important, emerging aesthetics that generate new configurations and diverse forms of relating to public place. This is why researchers needed to use different strategies and methodologies to understand these complex phenomena and relations both within and between different cities.

By applying the approaches mentioned above, space can be created where it is possible to read the social dynamics and transformations. To do this, we propose a comparative analysis of multiple cases, along with a methodological triangulation that includes recurrent observation, photographic analysis, and graphical production; the latter as an explanation of the previous two steps 


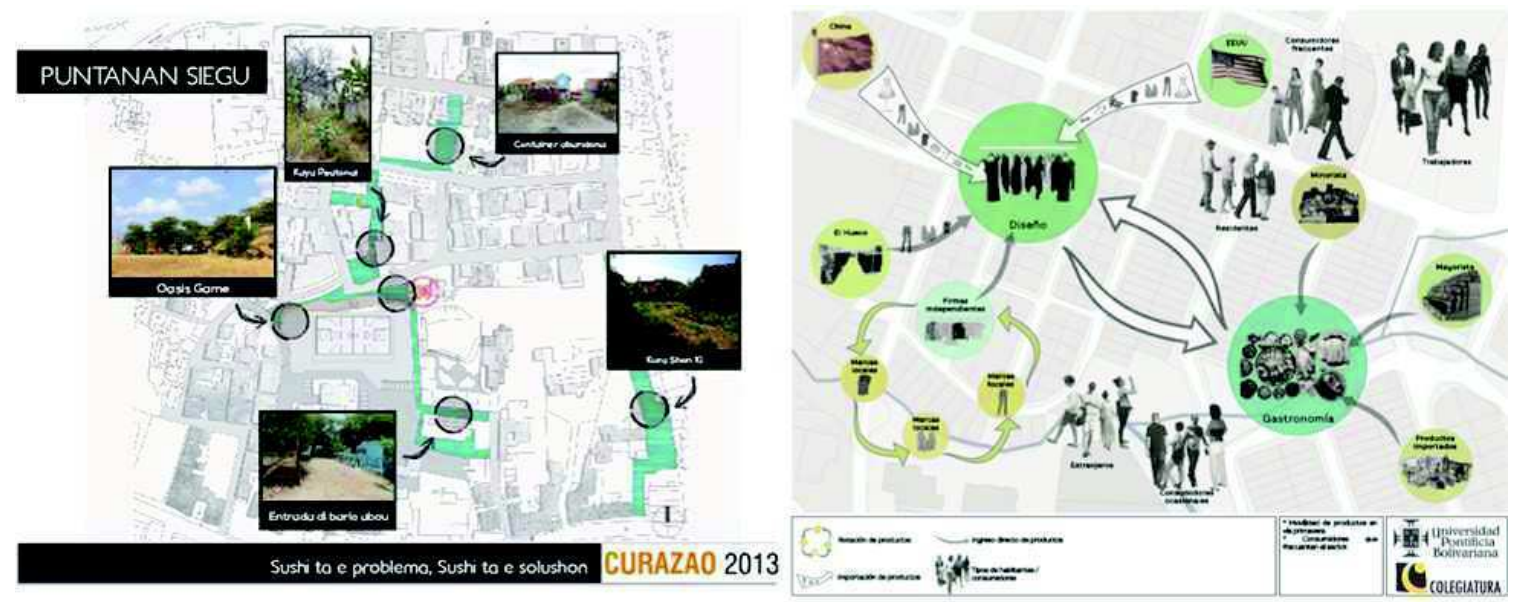

Figure 1.

Left: Sensory map of the intervention area in Willemstad, Curacao. By Sofia Saavedra Bruno. (Curacao.2013). Right: Sensory map of Via Primavera in Medellín. By Research group MCE. (Medellín. 2017)

of the triangulation. These visual sources are complemented by field diaries containing information arising from interviews that help with approaching community perceptions regarding spaces and their bonds of affection with them (Kuri \& Aguilar, 2006).

\section{Triangulating visual research methods}

When inquiring about this process, its impact and the inhabitants' relationship to a newly transformed space, researchers suggest using graphical research methods that allow collecting, evaluating, re-elaborating and establishing comparative criteria and identifying the repeated impacts caused by urban interventions. This makes the impacts' current characteristics and others to be considered in the future are taken into account. Observation and question-based methods are the simplest approaches used in urban transformation research, as they take into account different factors. If we understand observation both an ethnographic resource, we can connect it with the concept of being in the same place (space-object), as indicated by Kuri and Aguilar: "there are many ways of being in a place, observing an action. You can look through video recordings and photographs by interdisciplinary groups, chroniclers, from above or from below, with a panoptic vision or 'in situ' experiences, from the outside or from within” (2006, pág. 179)
Understanding change, development and spatial appropriation processes in each of the cities in which this exercise was performed, requires multiple and complex viewpoints and is not simply an exercise in formal analysis, allowing instead a simultaneous sensory and perceptual reflection on the contents of these spaces, to reach an understanding of the dynamics of change established there. As Kevin Lynch says: "Very often, our perception of the city is not continuous but rather partial, fragmented, mixed with other concerns. Almost every sense is active and the image is the combination of all of them". (190, pág. 10).

\section{Sensory mapping}

Researchers used different graphical tools, including drawings, to build a sensory map with the purpose of identifying the area where impacts occur, population mobility, use of space and behaviors; all based on how the senses perceive the urban space. Sensory mapping (See Figure 1), for example, allows researchers to express each phase of information collection and easily connect the perspectives obtained. When the senses are set to the task of discovering and recognizing reality, deletions, distortions, additions, and other changes with associational meaning can apply to their interpretations. However, this is not necessarily a bad thing, since they can be combined with other internal and external 

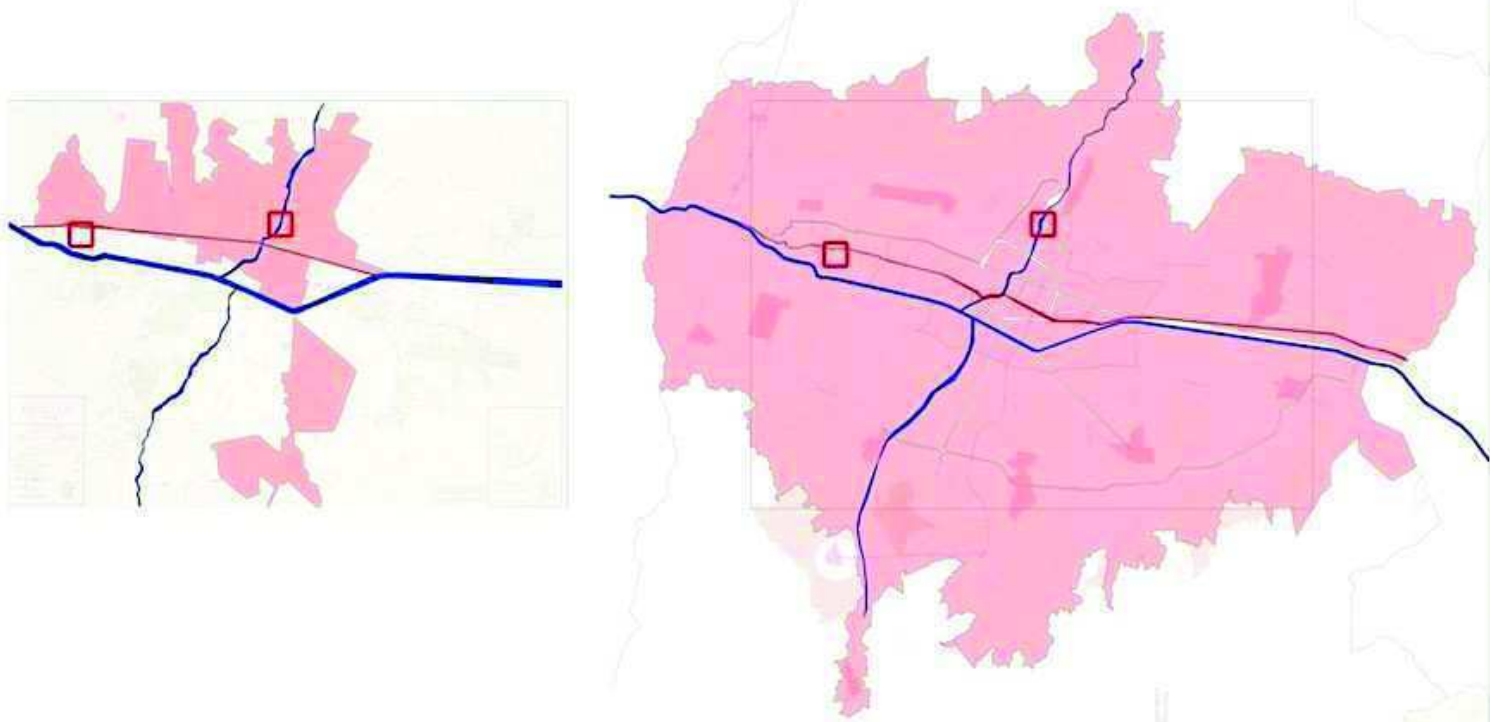

Figure 2.

[Collage by Leonardo Correa Velásquez]. (Medellín.1944). Collage made by redrawing blueprints of Medellin and drawings of the growth of structures within the city of Medellin. Digital archive. Planoteca de Planeación Metropolitana, Medellin.

interpretations to arrive at more conclusive results.

Comparing different sensory maps created in each of the five cities between the communities and the research group allows researchers to identify characteristics, social phenomena and recurrent development ideals the inhabitants had for their spaces, now transformed both positively and negatively.

\section{Drawing and re-drawing as a tool}

Drawing is the primary tool for rapprochement. As analysis tools, drawings can be divided into two groups: first, drawing as a form of inventory. Second, drawings which allow viewing the proportions and visual relationships between places and architectural pieces located there through the focus of interest of the person drawing. In the first group of drawing tools, that includes sensory mapping, and most of which are blueprints - technical drawings of the territory or the city, it is possible to clearly distinguish that infrastructure is the furniture and the scenarios which serve as physical determinants for spaces. We can understand the relationships between places and their connections to their immediate surroundings by plotting mobility flows (see figure 2 ) as the majority of the physical layouts of the cities studied are structured by lines and roads that have conditioned both a sense of territorial ownership and their neighborhoods, as stated by Jane Jacobs: "The streets and its sidewalks, the main public places of a city, are its most vital organs" (2011, pág. 55)

Through these drawings it can be seen how one repetitive policy for new public interventions is to widen public spaces that articulate transitions with buildings and their connections to the main infrastructure, road and landscape conditions. However, in some cases these are not targeted or correlated appropriately. It can also be seen how urban furniture is distributed throughout these spaces and how it connects to activities proposed for them. One can also highlight in these drawings the factors that oppress the spaces, such as noise or lack of infrastructure.

The second group of drawings that analyze places can be called sensory perspectives. Volumetric drawings for instance, which do not require dimensions, provide a proportional visualization of the ways in which places are set up and related to structures and the landscape, as well as the ways in which they are appropriated by residents and passersby. Through this group of drawings we can perceive a description of the place's atmosphere. 


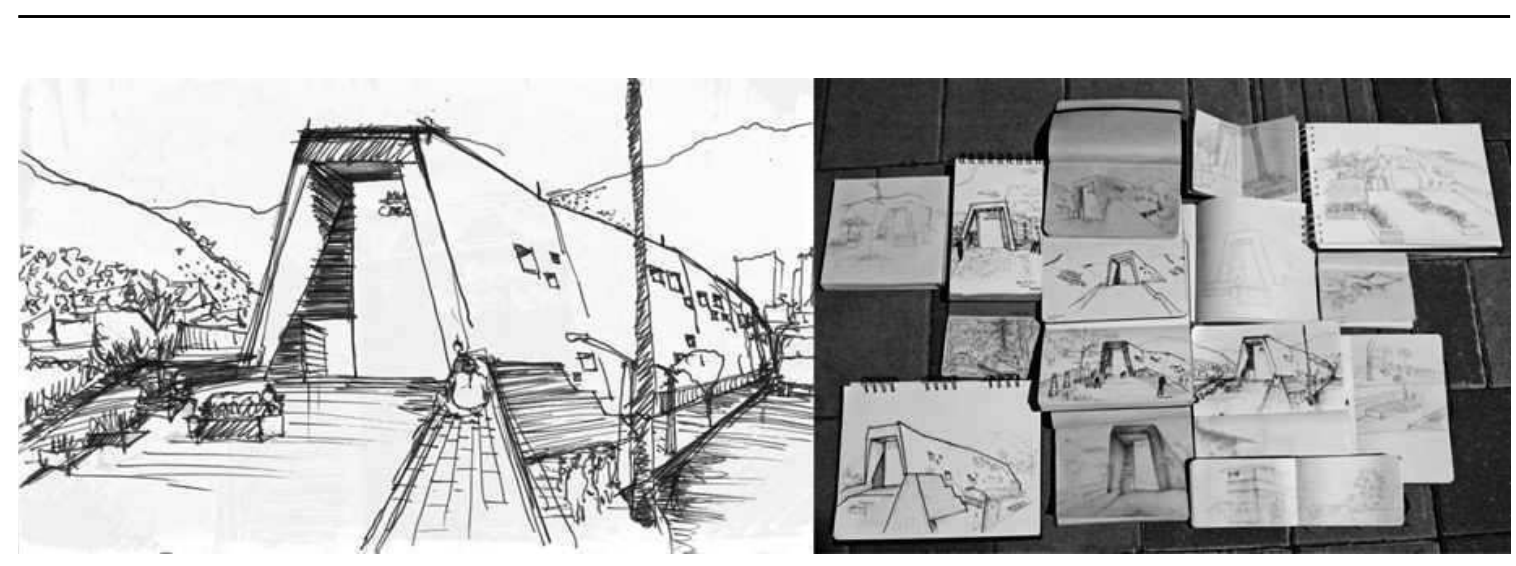

Figure 3.

[Drawings by multiple authors]. (Medellín.2014). Perspective drawings of the Casa de la Memoria building and its contextual relations. Event "Dibujar la Ciudad", Medellin.

"Atmosphere, character, and sensory qualities are becoming key factors in the definition of places, even from an economic perspective" (Zardini , 2005, pág. 24) (See figure 3).

We must clarify that, in these drawings, the recognition of the atmosphere corresponds to the unique structure of each place studied, and that behaviors and shapes are different in each case. However, the elements of these representations end up being the same (streets, sidewalks, furniture buildings), and those that change are weather, light, smell; just as Christian Norberg-Schulz mentioned when referring to the spirit of place, the Genius Loci.

\section{Photography as a research tool}

In general, we refer to photography as a method that applies to a wide range of research strategies: from analyzing and interpreting photos taken by research groups to having inhabitants take photos of themselves in relation to the space they inhabit. It is important to acknowledge that,

"Any photograph may have ethnographic interest, significance or meanings at a particular time or for a specific reason. The meanings of photographs are arbitrary and subjective; they depend on who is looking. The same photographic image may have a variety of (perhaps conflicting) meanings invested in it at different stages of ethnographic research and representation, as it is viewed by different eyes and audiences in diverse temporal historical, spatial, and cultural contexts." (Pink, Doing Ethnography: Images, Media and
Representation in Research, 2001, pág. 51)

Pink encourages the use of visual technology, but urges the researcher to be versed on what may transpire as a result of combining this method with qualitative research.

The use of images allows a complex understanding of social phenomena based on a visual appropriation of spaces along with new and existing records, building parallels between historic and current user and researcher perspectives. This visual appropriation is a starting point for developing collective visions of the city and how it connects to the social purpose behind macro projects or urban interventions. During the phase of collecting information, researchers used two types of photography: (1) environmental photography with qualitative aspects that encourage evaluating relationships between the space and its users, daily life, and overall atmosphere; and (2) a technique with more quantitative characteristics that helps understand the spaces' physical proportions and morphological behavior. All this is done by using historical photographic archives, and comparing them to photographs taken by the researchers in the field so as to understand different narratives and social phenomena.

As John Berger proposes, the first type of picture used are current-day ones that serve as research tools for describing spatial relationships, trying to find "defining moments" that bring us to events related to the ways of life and appropriation of these places by residents and passersby. Likewise, these images allow describing and identifying the spaces' textures, colors and perceivable characteristics, which 

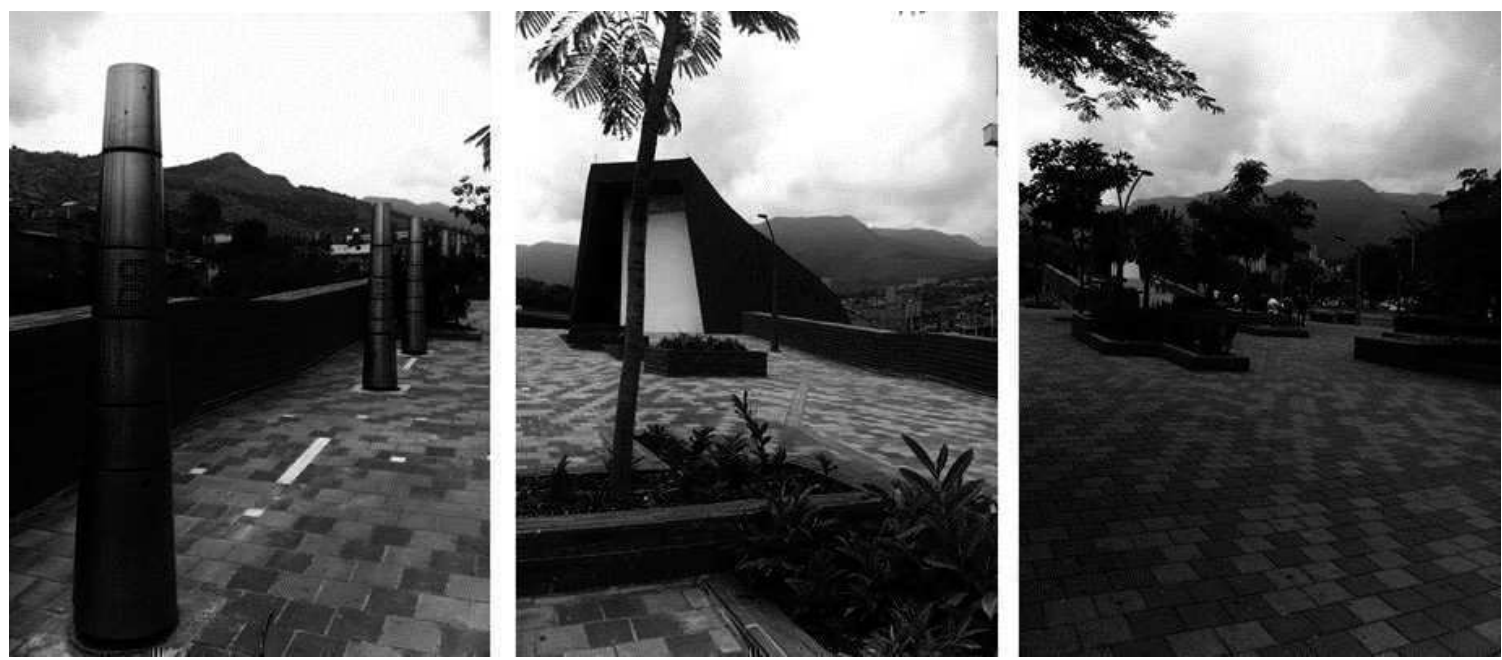

Figure 4.

[Photographs by Ana Elena Builes Vélez and Leonardo Correa Velásquez]. (Medellín.2014). Field work on the path of Casa de la Memoria, located along the development axis of the Santa Elena stream, Medellin

can point to the aesthetic qualities of the researched environments and population that inhabits them. (Berger, 2000) (See figure 4)

These photographs provide support for drawings and analysis presentations, wherein the correspondence between the blueprints' quantitative emphasis and details to be found in the photographs can be seen.

The second type of photograph incorporated into the analysis, are historical pictures taken by photographers with training in aesthetics and composition and can be found in the photographic archives of the cities where this analysis is performed. (See figure 5)

In these archive photographs researchers can find three factors that define the interests through which the reconstruction of these places was approached. The first one is related to the composition in terms of the figures and the ground; the second, to geometry in terms of vanishing points and the observer's position regarding image configuration; the third one has to do with the idea or concept related to the expression of the subject of the photograph, which refers directly to its context.

Memories are reconstructed by comparing historical photographs, with more recent images showing the progressive or radical transformation of those places. These changes can be described simultaneously from formal, historical and environmental points of view, by identifying the same places of interest or photographed objects and in certain cases with the same focal points in the photographs being compared. It is also important to mention that in many comparative analyses, photographs can be correlated by identifying the observer's point of view and his or her position within the blueprint of the place being studied. In this way information from several pictures can be grouped and overlaid.

Visualizing photographs simultaneously and comparatively - with the goal of establishing criteria for identifying common characteristics amongst the images - is a method of visual analysis belonging to the historiography of the art and its application as a strategy for iconographic analysis. It establishes the basis upon which images are formally studied. This type of analysis requires being complemented by a reconstruction of the cultural images of the environment. This could be done through documents, graphs or additional images.

In this manner, images -and particularly photographs- are not isolated representations in a process of visual analysis. On the contrary, they play a key role in the process of understanding the impact and transformations a place is subjected to by identifying every formal variable that can be extracted from the photograph and simultaneously relating such variables to external documents. Reading and interpreting photographs requires understanding initially that the process will be -very often- tied to the researcher's (or the person analyzing the photograph's) subjective 


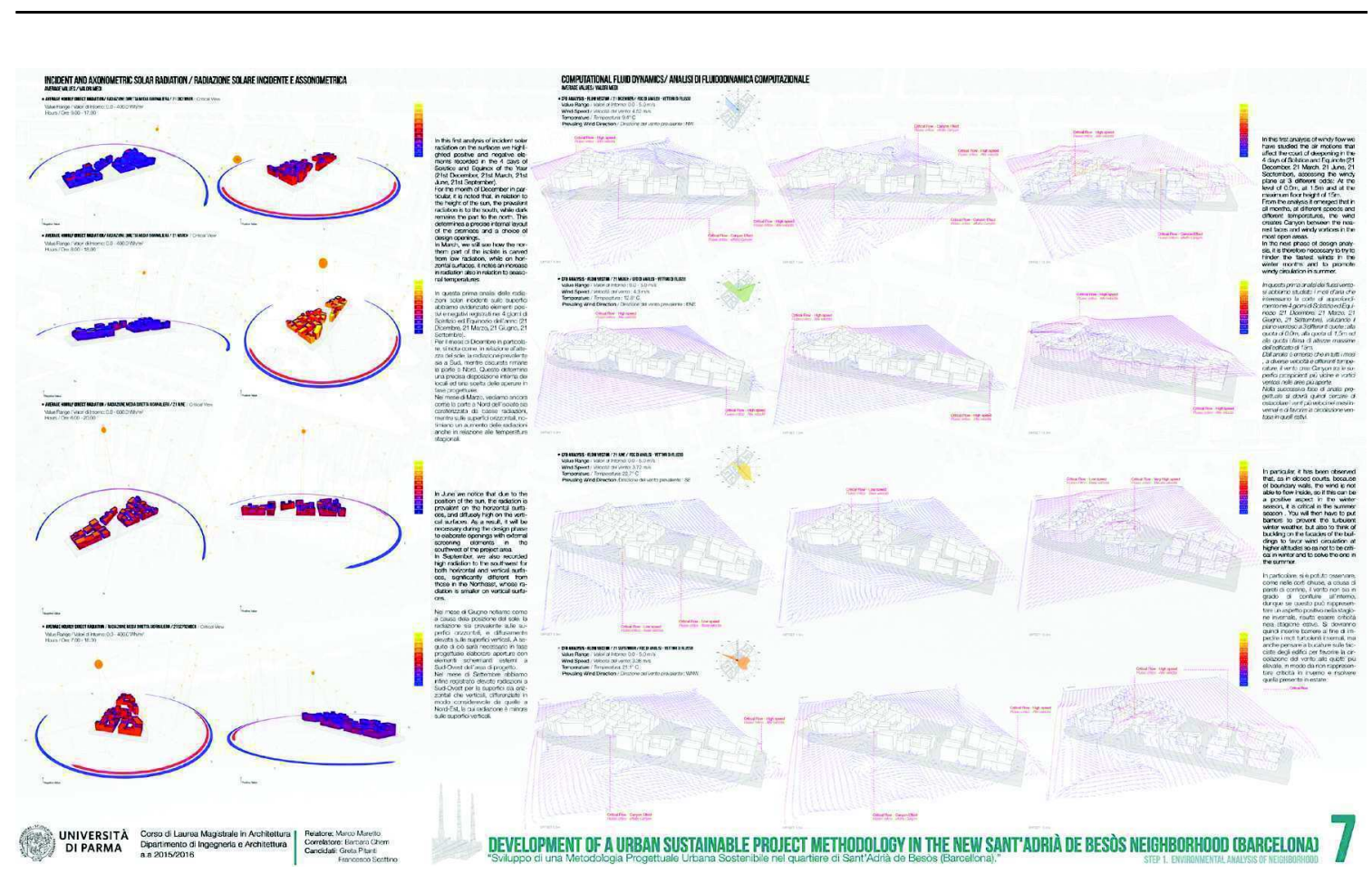

Figure 5.

Collage. [Photograph by Rafael Mesa]. (Medellín.1900). Historical Photograph of the Santa Elena stream's development axis. Digital archive. Biblioteca Pública Piloto, Medellín. Retrieved from: http://www.bibliotecapiloto.gov.co/archivo-fotografico. [Photograph by Rodríguez]. (Medellín.1900). Junín bridge. Digital archive. Biblioteca Pública Piloto, Medellín. Retrieved from: http://www. bibliotecapiloto.gov.co/archivo-fotografico.

critical and interpretative position. It takes a great deal of effort to minimize this risk factor, but becomes necessary when seeking to establish an initial analytical approach through a contextual study of the image. Sarah Pink, in her book Doing Ethnography: Images, Media and representations, recognizes this as an important issue, but also encourages researchers to use visual methods in any context of researcher. So for her "Images are 'everywhere'. They permeate our academic work, everyday lives, conversations and dreams" (Pink, Doing Ethnography: Images, Media and Representation in Research, 2001, pág. 17)

The first step towards removing oneself from a viewpoint that is "too subjective", is understanding the historical and social background of the photograph's author and acquiring knowledge of the techniques he or she used. This allows the critic to approach a more accurate interpretation of the original conditions under which the work was created.

Having acquired a less subjective opinion, the critic can now focus on a context governed by form.
Compositional patterns define every image and make it possible to study them from a formal point of view. However, there are many aspects to and opinions on how to approach a formal analysis. Since the researcher analyzes the image through a filter defined by his or her own perceptions, we can conclude interpretational and subjective points of view now play a crucial role in the process. In consequence, finding the exact description and analysis of an image becomes a great challenge as no linguistic guidelines or precise language exists for decoding the images' meaning.

"This images are actually capable of stealing reality because, above all, a photograph is not simply an image (in the same sense that a painting is), an interpretation of reality; it is also a vestige, a direct trace of reality, like a footprint or a mortuary mask." (Sontag, 2006, pág. 216)

The third reading level is more a correlation between the previous two aspects. It studies the articulation of space and time by looking at types of perspective and rhythmical tensions 
in an attempt to interpret the inner meanings articulated by the image.

The final step is to analyze the message presented by the image. To do this, we must identify key factors pertaining to the photographer's vision and intention and the way his or her image is constructed. These factors include: the location the photograph was taken, the photographer's location, and his or her frame of interest (what the photographer decides to frame and in what direction). All images are influenced and mediated by the intentional actions of their author and the reasoning behind them.

\section{Graphical reconstruction and architectural drawing strategies}

Finally, a graphical reconstruction is used as a tool for identifying urban and architectural strategies that suggest connections between usage and the user, seeking to understand and confront the intentions of the urbanists responsible for project development and infrastructure construction. It behaves as a temporal and spatial tracking method.

The exercise of redrawing architectural and urban structures is done to achieve a far wider understanding of the studied area, acknowledging the relationships between the city's structures through morphological drawings, shapes, traces and buildings.

Methodologically, the way in which predrawn urban maps are presented, responds to a type of organization known technically as grids. The different planes (depending on their characteristics, focus or topic) are placed relationally on columns or rows. Grids allow communicating and displaying simultaneous issues and their correlations.

This method of presenting information analytically is one of a group of interdisciplinary tools that appeared with the modern movement. It remains valid to the point it can be used for studying development processes and urban transformations as it is able to identify the individual characteristics of each case study. This facilitates comparisons with other cases and simultaneous visualization for continuously validating other studies.

Grids - in most cases - allow time lapse- based evaluations and display the impact and results of putting different strategies and urban development projects in place. They allow an optimal visualization of the structures in the cities being studied and how they compare to each other, with mountains or rivers as initial conditioners for implementation, and existing transportation routes and infrastructure as a second parameter.

The way the city's structure is superimposed upon the territories morphological features directly conditions -mostly negatively- all issues of appropriation and relations within the cities that are being the studied. This negative effect results from the current view of development as an alternative driven by economic benefits. All of this, added to a rapid and inadequate territorial appropriation, is diminishing the importance of having structures that allow for healthy social exchanges and interactions with the landscape.

Using architectural tools, such as drawings and blueprints, we can understand a location's distance, orientation and scale, the spatial characteristics of the areas studied, and can then, by comparing past and present drawings of these places, define a record of the changes that have occurred in its urban layout, road connections and public space. (See figure 6)

The first level of analysis is to graphically locate "trigger pieces", or public buildings built in the last 10 years, in urban blueprints, structured from aerial views where topographical appropriations, relationships with natural structures, changes in paths and increasing or decreasing public space can be compared. In this type of blueprints we can also identify uses and variations that have arisen in relation to urban transformations experienced simultaneously by different places.

The second group of drawings are technical detail blueprints, wherein we can establish a relation between the human scale and the context in order to study the relations of scale between pedestrians, buildings and public spaces. These drawings are mostly sections, quantitative representations of a building's walls, platform, furnishings and ceiling. Analyzing them will identify the spatial strategies used by architects and planners to establish the living conditions and usage of public spaces in relation to the buildings and areas in which they are located. 


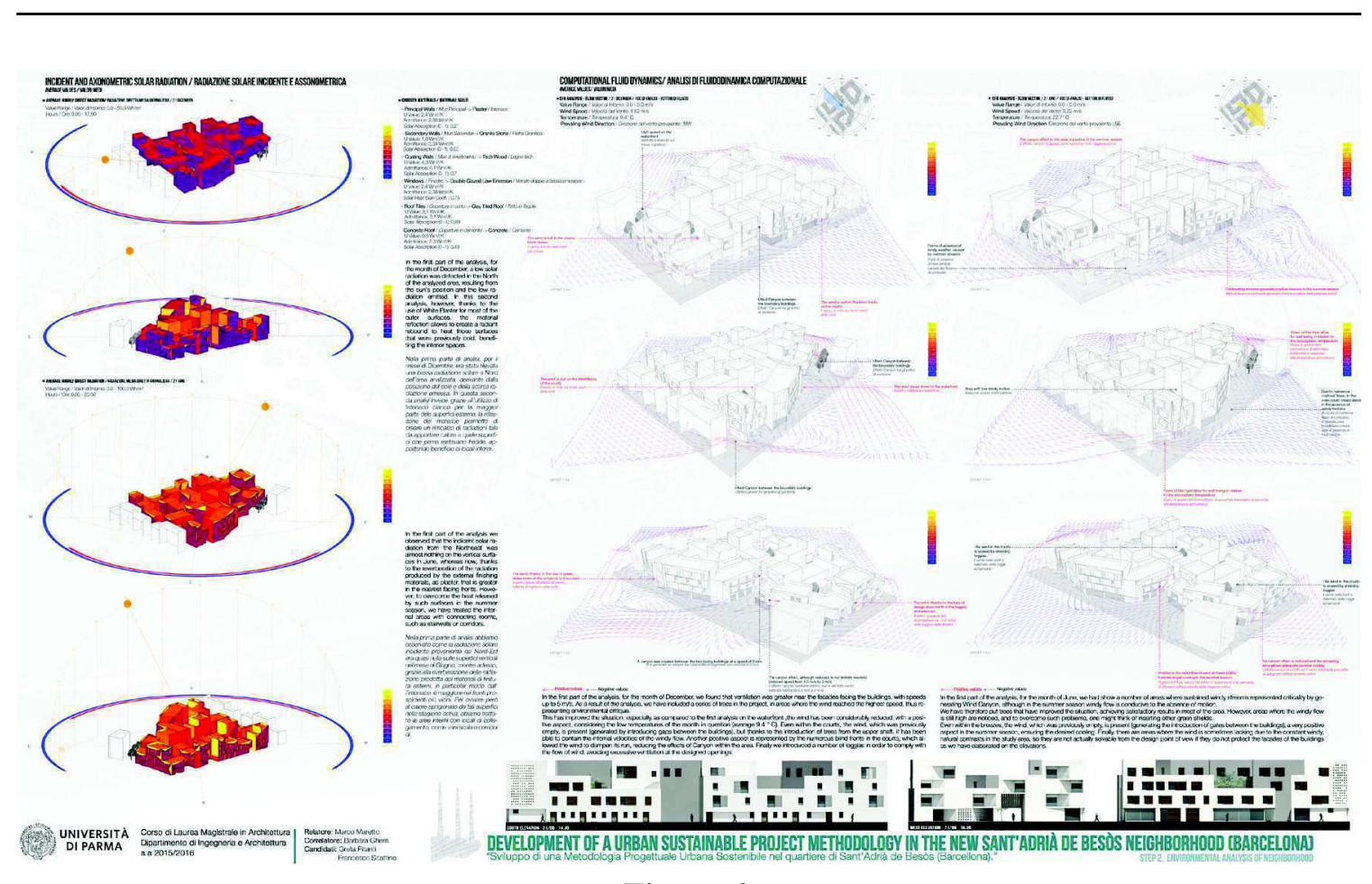

Figure 6.

[Blueprints by Leonardo Correa Velásquez]. (Medellín. 205-2015). Comparative blueprints of areas where trigger pieces were built. Centro Cultural Moravia and Casa de la Memoria, Medellin.

It's important to note that, although these exercises provide data on the urban and architectural morphology of the sectors studies, these results can't simply be formal. There is evidence that the overall interest of the governments that plan cities includes the definition of strategies related to the development of said cities by designing roads and public spaces. Although this strategy provides information on physical conditions, it doesn't reflect social realities with any depth.

These three stages embrace the three dimensions considered in the research to build a wider perspective of the problem being analyzed:

a. Morphological space: consists of all that is observable as "dead areas" with no human interactions: land, natural environment, buildings, equipment, etc. All of these resulting from human interventions.

b. Social, political and economic space: refers to urban practices, citizen participation and private and public behavioral analysis.

c. A connection between the previous two dimensions: the other/others in relation to the space; what/how people represent, perceive and inhabit it.

\section{Conclusion}

The three research tools analyzed in this paper: mapping, drawing and photography, define a recurrent method that creates an effect of distance, which increases the effect of designation (Pink \& Alonso, 2004) and shows how urban dynamics can articulate submerged realities discussed through the visual sources that were exposed, allowing a closer relationship between the research and the representation that has been made. It is clear that a "static image" offers both advantages and disadvantages. It provides the researcher with the possibility of looking at a situation again from the point of view of any number of observers, expanding their social thinking

By simultaneously looking at various photographs and plans of intervention in different cities, we were able to identify reiterating development processes and similar reactions to urban transformations. The transformations undergone by Latin American cities in recent years have left deep marks mostly in the way formal and social structures are arranged and perceived.

In fact, perceiving each of the analyzed cities and their transformations is a complex 
exercise, since once runs the risk that the image built at first glance by a person with no prior knowledge of the city can be chaotic. Even so, this image may also approach the image of a city renewed through "social planning" instead of simply structural planning. The sensory mapping tool is of great help when approaching this image from a social point of view; it allows delving into what photographs, advertising campaigns or blueprints cannot describe: the "Genius Loci".

Photography is a way to understand times and record changes. Photographic productions are useful for building formal references that account for advancing urban production and architectural constructions, and also for revealing social practices and expressions of life throughout history. Currently, this way of using and producing photography is being adopted around the world, with an interest, not in simply registering large urban developments, but rather in the way in which people relate to the urban environment, their life stories, and the way these connect to economic and social conflict.

Any answer to such a complex question, such as the one posed by this research project, requires restating traditional research methods and involving other non-traditional ones, to thus acquire a global and more complete perspective of these phenomena. The senses, especially sight, allow researchers to analyze external occurrences. Visual exposure allows them to go farther and observe in greater depth other aspects presented by the culture and all the complex details in full. This is why we believe it is important to adopt, and in other cases restructure, other research method that involve a variety of tools to achieve a wider and more complex analysis and understanding of the problem.

\section{References}

Berger, J. (2000). Modos de ver. Barcelona: Gustavo Gilli .

Jacobs, J. (2011). Vida y muerte de las grandes ciudades. Madrid: Capitan Swing Libros.

Kuri, P., \& Aguilar, M. (2006). Pensar y habitar la ciudad: afectividad, memoria y significado en el espacio urbano contemporáneo.
Barcelona: Anthropos.

Lynch, K. (190). The Image of the City. Cambridge: MIT.

Pink, S. (2001). Doing Ethnography: Images, Media and Representation in Research. London: Sage.

Pink, S., \& Alonso, A. (2004). Working Images: Visual Research and Represetation in Etnography. London: Psychology Press.

Sontag, S. (2006). On Photography . México: Alfaguara.

Zardini, M. (2005). Toward a Sensorial Urbanism. Sense of the City. Montreal: Canadian Center for Architecture \& Lars Muller Publisers. 